\title{
Isocitrate Dehydrogenase 2 Suppresses the Invasion of Hepatocellular Carcinoma Cells via Matrix Metalloproteinase 9
}

\author{
Guo-Yan Tian ${ }^{\mathrm{a}}$ Shu-Fei Zang ${ }^{\mathrm{a}}$ Lei Wang ${ }^{\mathrm{a}}$ Yan Luo ${ }^{\mathrm{b}}$ Jun-Ping Shic \\ Guo-Qiang Louc
}

aThe Second Clinical Medical College, Zhejiang Chinese Medicine University, Hangzhou, 'DInstitute of Translational Medicine, the Affiliated Hospital of Hangzhou Normal University, Hangzhou, 'Department of Liver Disease, the Affiliated Hospital of Hangzhou Normal University, Hangzhou, China

\section{Key Words}

Isocitrate dehydrogenase 2 (IDH2) - NF-KB - IkB - Matrix metalloproteinase 9 (MMP9) • Hepatocellular carcinoma (HCC) $\bullet$ Metastases

\begin{abstract}
Background/Aims: Isocitrate dehydrogenase 2 (IDH2) is a mitochondrial NADP-dependent isocitrate dehydrogenase, and has been found to be a tumor suppressor in several types of tumors. However, the roles of IDH2 in hepatocellular carcinoma (HCC) as well as underlying mechanisms remain unknown. Methods: The IDH2 and matrix metalloproteinase 9 (MMP9) levels in the specimens from 24 HCC patients were investigated by Western blot and ELISA, respectively. Their relationship was examined by correlation analyses. Patient survival with high IDH2 levels and low IDH2 levels was compared. IDH2 levels and MMP9 levels were modified in a human HCC cell line. The effects of IDH2 or MMP9 modulation on the expression of the other were analyzed. The effects of IDH2 on cell invasion were analyzed in a transwell cell invasion assay. The dependence of nuclear factor $\mathrm{KB}(\mathrm{NF}-\mathrm{KB})$ signaling was examined using a specific inhibitor. Results: The IDH2 levels significantly decreased in HCC, and were lower in HCC with metastases, compared to those without metastases. IDH2 levels inversely correlated with MMP9 levels in HCC. HCC patients with Low IDH2 had lower 5-year survival. MMP9 levels did not regulate IDH2 levels, while IDH2 inhibited MMP9 levels in HCC cells, in a NF-KB signaling dependent manner, possibly through iкB, to suppress HCC cell invasion. Conclusions: Down regulation of IDH2 may promote $\mathrm{HCC}$ cell invasion via NF-KB-dependent increases in MMP9 activity. IDH2 may be a potential therapeutic target for HCC.

Jun-Ping Shi and Guo-Qiang Lou

Department of Liver Disease, the Affiliated Hospital of Hangzhou Normal University, 126 Wenzhou Road, Hangzhou 310015, (China)

Tel.+8657188358060, E-Mail davidshi0571@126.com,E-Mail guoqiang_lou@163.com
\end{abstract}

KARGER 125 


\section{Cellular Physiology Cell Physiol Biochem 2015;37:2405-2414

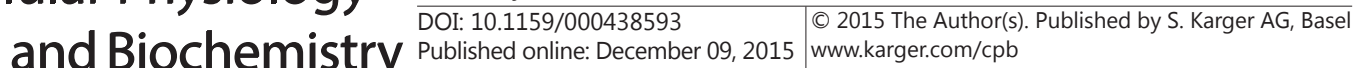 \\ Tian et al.: IDH2 Suppresses HCC Invasion via MMP9}

\section{Introduction}

Hepatocellular carcinoma (HCC) is a prevalent primary malignant tumor, characterized by aggressive invasion, early metastasis and resistance to existing chemotherapeutics [1-4]. In spite of the continuous increases in 5-year survival for HCC due to advances in combined therapy with surgery, radiotherapy and chemotherapy, some patients still suffer from poor outcome due to malignant growth and metastases of HCC [1-4]. Thus, a further understanding of the molecular mechanisms underlying the progression and metastases of HCC would improve the current therapy [5-13].

NADP (+)-dependent isocitrate dehydrogenases (IDH) include IDH1 and IDH2, which catalyze oxidative decarboxylation and produces $\mathrm{CO}_{2}$, NADPH and $\alpha$-ketoglutarate from isocitrate in the mitochondria [14-19]. NADPH is a vital cofactor in fat and cholesterol biosynthesis and glutathione metabolism. Mitochondrial IDH plays an important role in cellular defense against oxidative damage by providing NADPH, which is required to regenerate the glutathione levels in the mitochondria [14-19]. Reactive oxygen species (ROS) are produced in mitochondria, and are involved in the pathogenesis of many human disorders [14-19]. Increased ROS levels promote cellular oxidative stress that contributes to various aspects of malignant tumors, including carcinogenesis, aberrant growth, angiogenesis and metastasis. Although IDH has been found to decrease in some types of cancer, resulting in defects in the mitochondrial redox balance and cellular oxidative damage through NAPDH $[20,21]$, the role of IDH2 in HCC remains unknown.

Tumor cell growth and invasion are regulated by a network of factors, among which nuclear factor $\kappa \mathrm{B}(\mathrm{NF}-\kappa \mathrm{B})$ is a critical one that regulates the expression of various genes involved in immunity, stress responses, inflammation and the inhibition of apoptosis, thus providing appropriate conditions for tumor cell progression [22-24]. NF- $\kappa B$ is constitutively activated in some tumor cells, including HCC cells, and contributes to the maintenance of the highly proliferative malignant phenotype as well as cellular invasion [22-24]. NF- $\kappa B$ regulates several metastasis-related matrix metalloproteinases (MMPs), such as MMP1, MMP3, and MMP9 [25-27]. MMP9 is an important invasion- or metastasis-related NF- $\mathrm{B}$ target gene that is directly associated with the metastatic processes in cancers [28-32].

In the current study, we found that the IDH2 levels significantly decreased in HCC, and were lower in HCC with metastases, compared to those without metastases. IDH2 levels inversely correlated with MMP9 levels in HCC. HCC patients with Low IDH2 had lower 5-year survival. MMP9 levels did not regulate IDH2 levels, while IDH2 inhibited MMP9 levels in HCC cells, in a NF- $\kappa B$ signaling dependent manner, possibly through $i \kappa B$, to suppress HCC cell invasion.

\section{Materials and Methods}

Patient tissue specimens

A total of 24 resected specimens (paired with HCC tissue and adjacent non-tumor tissue (NT)) collected for this study. In all 24 samples, 12 were with distal metastases, while the other 12 were not. All specimens had been histologically and clinically diagnosed at the Jinan Central Hospital of Shandong University from 2008 to 2014. For the use of these clinical materials for research purposes, prior patient's consents and approval from the Institutional Research Ethics Committee were obtained.

\section{Cell lines}

HepG2 is a human HCC cell line, which was purchased from American Type Culture Collection (ATCC, Rockville, MD, USA), and cultured in Dulbecco's modified Eagle's medium (DMEM, Invitrogen, Carlsbad, CA, USA) supplemented with 15\% fetal bovine serum (FBS; Sigma-Aldrich, St Louis, MO, USA) in a humidified chamber with $5 \% \mathrm{CO}_{2}$ at $37^{\circ} \mathrm{C}$. MG132 (Sigma-Aldrich) is a specific NF- $\kappa$ B signaling inhibitor, and was used at $5 \mu \mathrm{mol} / \mathrm{l}$.

\section{KARGER}




\section{Cellular Physiology Cell Physiol Biochem 2015;37:2405-2414 \begin{tabular}{l|l|l|l}
\hline DOI: 10.1159/000438593 & (c) 2015 The Author(s). Published by S. Karger AG, Basel \\
\hline
\end{tabular} and Biochemistry Published online: December 09, 2015 www.karger.com/cpb \\ Tian et al.: IDH2 Suppresses HCC Invasion via MMPg}

\section{Plasmid transfection}

IDH2 and MMP9 constructs were generated by sub-cloning PCR-amplified full-length human IDH2 cDNA or MMP9 cNDA into pcDNA3.1EGFR. For depletion of IDH2 or MMP9, corresponding human short hairpin small interference RNA (shRNA) sequences were cloned into pcDNA3.1EGFR to generate the shRNA construct. Sequence: shIDH2: 5'-GTG GAC ATC CAG CTA AAG TAT-3'; shMMP9: 5'-ACC ACA ACA UCA CCU AUU GTT-3'. Transfection was performed with Lipofectamine 2000 reagent (Invitrogen), according to the instructions of the manufacturer. Transfected cells expressing IDH2, or shIDH2, or MMP9, or shMMP9, were selected by flow cytometry based on GFP. The cells that were transfected with plasmids carrying scrambled sequence were used as controls.

\section{Western blot}

The protein was extracted from the specimens from patients or from cultured cells, in RIPA lysis buffer (1\% NP40, 0.1\% SDS, $100 \mu \mathrm{g} / \mathrm{mL}$ phenylmethylsulfonyl fluoride, 0.5\% sodium deoxycholate, in PBS) on ice. The supernatants were collected after centrifugation at $12,000 \times \mathrm{g}$ at $4^{\circ} \mathrm{C}$ for 20 min. Protein concentration was determined using a BCA protein assay kit (Bio-rad, China), and whole lysates were mixed with $4 \times$ SDS loading buffer $(125 \mathrm{mmol} / \mathrm{l}$ Tris-HCl, $4 \%$ SDS, $20 \%$ glycerol, $100 \mathrm{mmol} / \mathrm{l}$ DTT, and $0.2 \%$ bromophenol blue) at a ratio of $1: 3$. Samples were heated at $100^{\circ} \mathrm{C}$ for $5 \mathrm{~min}$ and were separated on SDSpolyacrylamide gels. The separated proteins were then transferred to a PVDF membrane. The membrane blots were first probed with a primary antibody. After incubation with horseradish peroxidase-conjugated second antibody, autoradiograms were prepared using the enhanced chemiluminescent system to visualize the protein antigen. The signals were recorded using X-ray film. Primary antibodies were rabbit anti-IDH2 (Millipore, Billerica, MA, USA), anti-p65, (Cell signaling, San Jose, CA, USA), anti-iкB (Cell signaling), antiiNOS (Cell signaling), anti-MMP9 (Cell signaling) and anti- $\alpha$-tubulin (Cell Signaling). Secondary antibody is HRP-conjugated anti-rabbit (Jackson ImmunoResearch Labs, West Grove, PA, USA). $\alpha$-tubulin was used as a protein loading control. Blotting images were representative from 5 repeats. Densitometry of Western blots was quantified with NIH ImageJ software (Bethesda, MD, USA).

\section{Quantitative RT-PCR}

Total RNA was extracted from cultured cells with RNeasy kit (Qiagen, Hilden, Germany), respectively. Complementary DNA (cDNA) was randomly primed from $2 \mu \mathrm{g}$ of total RNA using High-Capacity cDNA Reverse Transcription Kit (Applied Biosystems, Foster City, CA, USA). RT-qPCR was subsequently performed in triplicate with QuantiTect SYBR Green PCR Kit (Qiagen). All primers were purchased from Qiagen. Data were collected and analyzed using $2^{-\Delta \Delta \mathrm{Ct}}$ method for quantification of the relative mRNA expression levels. Values of genes were first normalized against $\alpha$-tubulin, and then compared to the experimental controls.

\section{MMP9 ELISA and activity assay}

The HCC cells were seeded in six-well plates and incubated at $37^{\circ} \mathrm{C}$. After $24 \mathrm{~h}$, the medium was removed. Then, the cells were washed and incubated in serum-free medium for $48 \mathrm{~h}$. The MMP9 amount and activity in the media were detected using MMP9 ELISA kit (R\&D Systems, Los Angeles, CA, USA) and Fluorokine E Human MMP9 Activity Assay kit (R\&D Systems), respectively, according to the manufacturer's protocol.

\section{Transwell cell invasion assay}

Cells $\left(10^{4}\right)$ were plated into the top side of polycarbonate transwell filter coated with Matrigel in the upper chamber of the BioCoatTM Invasion Chambers (Becton-Dickinson Biosciences, Bedford, MA, USA) and incubated at $37^{\circ} \mathrm{C}$ for 22 hours. The cells inside the upper chamber with cotton swabs were then removed. Migratory and invasive cells on the lower membrane surface were fixed, stained with hematoxylin, and counted for 10 random 100X fields per well. Cell counts are expressed as the mean number of cells per field of view. Five independent experiments were performed and the data are presented as mean \pm standard deviation (SD).

Statistical analysis

All data were statistically analyzed using one-way ANOVA with a Bonferroni correction, followed by Fisher's Exact Test for comparison of two groups (GraphPad Prism, GraphPad Software, Inc. La Jolla, CA, 


\section{Cellular Physiology Cell Physiol Biochem 2015;37:2405-2414 \\ \begin{tabular}{ll|l} 
DOI: 10.1159/000438593 & 2015 The Author(s). Published by S. Karger AG, Basel \\
www.karger.com/cpb
\end{tabular} \\ Tian et al.: IDH2 Suppresses HCC Invasion via MMP9}

USA). Bivariate correlations were calculated by Spearman's Rank Correlation Coefficients. Kaplan-Meier curves were sued to analyze the patient survival by IDH2 levels. All values are depicted as mean \pm standard deviation and are considered significant if $\mathrm{p}<0.05$.

\section{Results}

Decreased IDH2 and increased MMP9 are detected in HCC specimens

We examined the levels of IDH2 by Western blot, and the levels of MMP9 by ELISA on paired HCC tumor tissue (HCC) and the adjacent non-tumor normal tissues (NT) from the patients' specimens. Moreover, HCC was further separated into 2 groups, according to the presence of distal metastases (MS+) or not (MS-). We found that HCC contained significantly lower levels IDH2 (Fig. 1A) and significantly higher levels of MMP9 (Fig. 1B), compared to NT. Moreover, the IDH2 levels in HCC with distal metastases were significantly lower than HCC without distal metastases (Fig. 1A), and the MMP9 levels in HCC with distal metastases were significantly higher than HCC without distal metastases (Fig. 1B).

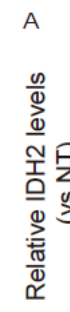

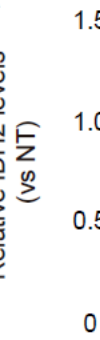
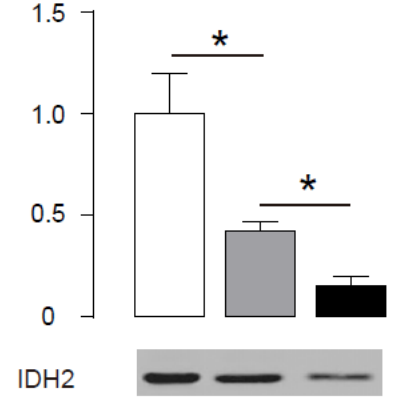

a-tubulin

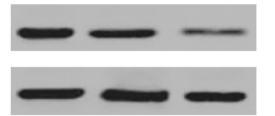

NT

$\mathrm{HCC}$

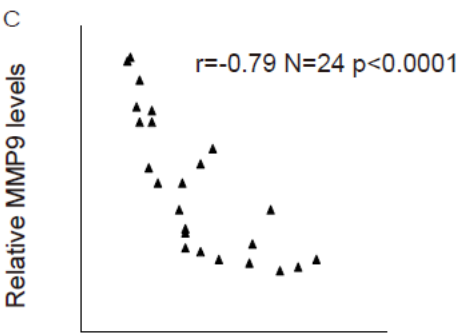

Relative IDH2 levels

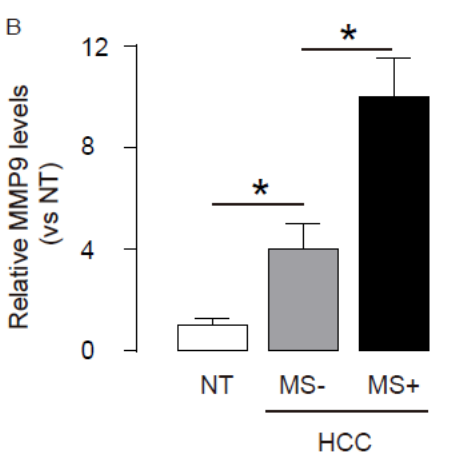

$50 \mathrm{kDa}$

D

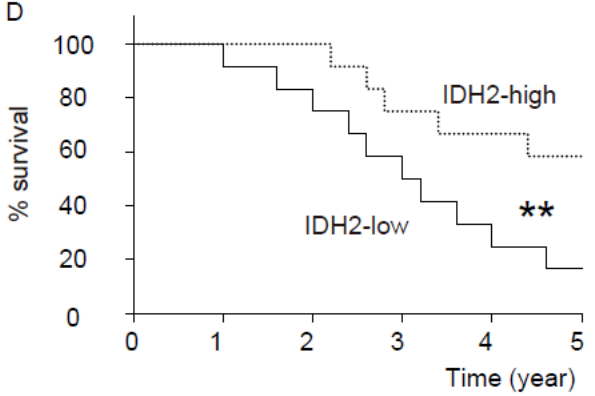

Fig. 1. Correlated decreased IDH2 and increased MMP9 in HCC. (A-B) Western blot for IDH2 (A) and ELISA for MMP9 (B) was performed on paired HCC tumor tissue (HCC) with/without metastases (MS+; MS-) and the adjacent non-tumor normal tissues (NT) from the patients. (C) A correlation test between IDH2 and MMP9 levels was performed in 24 HCC patients. A strong inverse correlation was detected $(\gamma=-0.79$, $\mathrm{p}<0.0001, \mathrm{~N}=24)$. (D) The 24 HCC patients were followed-up for 5 years. The median value of 24 cases was chosen as the cutoff point for separating IDH2-high cases $(n=12)$ from IDH2-low cases $(n=12)$. KaplanMeier curves were performed to evaluate the overall survival of the HCC patients, based on IDH2 levels. ${ }^{*} \mathrm{p}<0.05$. ${ }^{* *} \mathrm{p}<0.01$. 


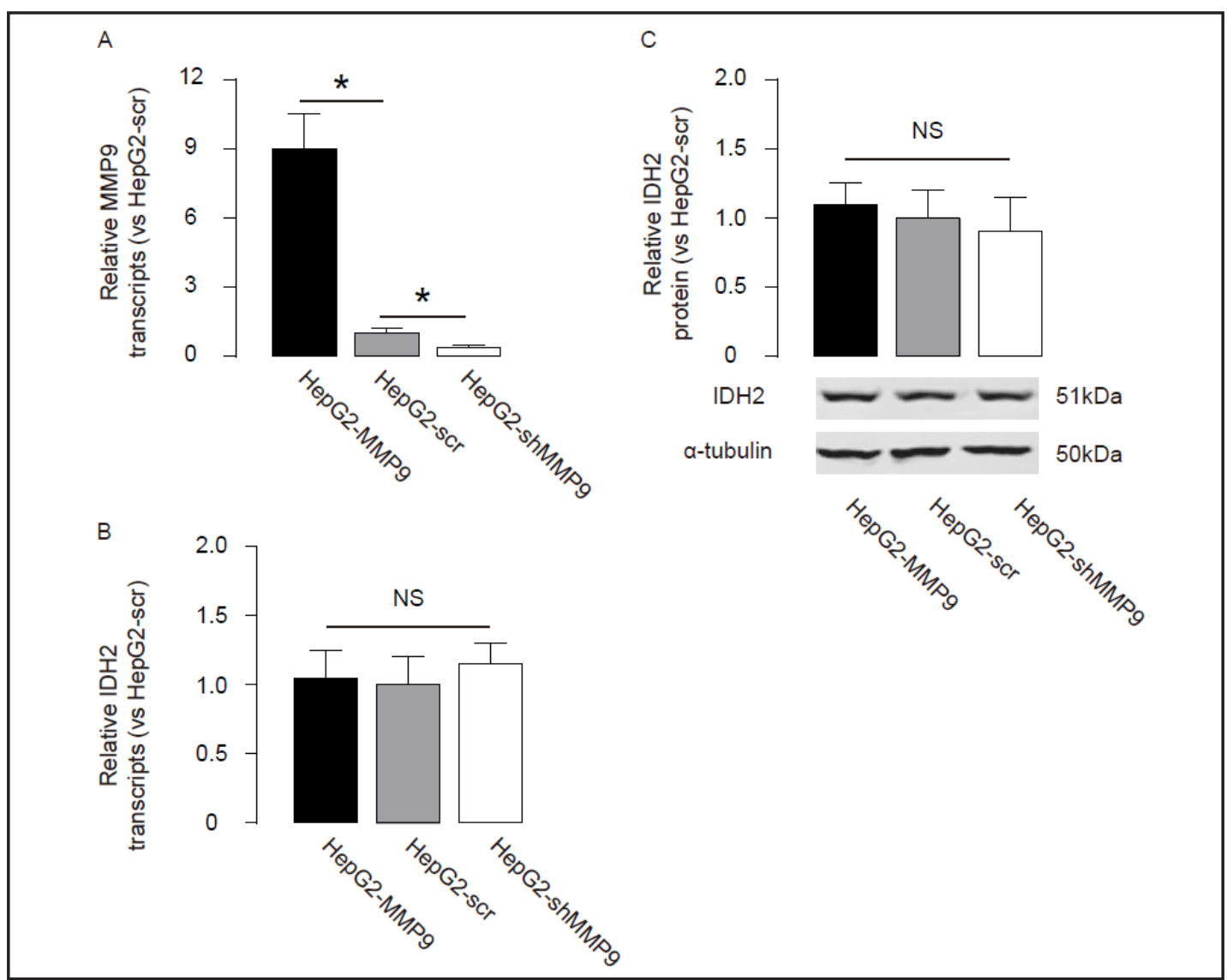

Fig. 2. MMP9 does not regulate IDH2 in HCC cells. We either overexpressed MMP9 by expression of MMP9 transgene (HepG2-MMP9), or inhibited MMP9 by expression of MMP9 shRNA (HepG2-shMMP9), through lipofectamine-mediated transfection of HepG2 cells. The HepG2 cells were also transfected with a plasmid carrying a scrambled sequence as a control (HepG2-scr). (A) The overexpression or inhibition of MMP9 in HepG2 cells was confirmed by RT-qPCR. (B-C) IDH2 levels in MMP9-modified HepG2 cells, by RT-qPCR (B), and by Western blot (C). ${ }^{*} \mathrm{p}<0.05$. NS: non-significant, $\mathrm{N}=5$.

IDH2 and MMP9 levels are inversely correlated in HCC

To figure out the relationship of IDH2 and MMP9 levels in HCC, we performed a correlation test in 24 HCC patients. A strong inverse correlation was detected (Fig. 1C, $\gamma=$ $-079, p<0.0001, N=24$ ), suggesting a possible regulatory relationship between IDH2 and MMP9. Next, we investigated whether the levels of IDH2 may correlate with overall survival of HCC patients. The 24 patients were followed-up for 5 years. The median value of all 24 cases was chosen as the cutoff point for separating IDH2-high cases $(n=12)$ from IDH2-low cases $(\mathrm{n}=12)$. Kaplan-Meier curves were performed, showing that IDH2-low HCC patients had a worse 5-year survival, compared to IDH2-high HCC patients (Fig. 1D).

\section{MMP9 does not regulate IDH2 in HCC cells}

In order to examine the relationship between IDH2 and MMP9, we used HepG2, which is the most widely used human HCC cell line, in our study. We either overexpressed MMP9 by expression of MMP9 transgene (HepG2-MMP9), or inhibited MMP9 by expression of MMP9 shRNA (HepG2-shMMP9), through lipofectamine-mediated transfection of HepG2 cells. The HepG2 cells were also transfected with a plasmid carrying a scrambled sequence as a control (HepG2-scr). The overexpression or inhibition of MMP9 in HepG2 cells was confirmed by RTqPCR (Fig. 2A). We found that the alteration of MMP9 levels in HepG2 cells did not alter IDH2 
Fig. 3. IDH2 inhibits MMP9 in HCC cells. We either overexpressed IDH2 by expression of IDH2 transgene (HepG2-IDH2), or inhibited IDH2 by expression of IDH2 shRNA (HepG2-shIDH2), through lipofectamine-mediated transfection of HepG2 cells. The HepG2 cells were also transfected with a plasmid carrying a scrambled sequence as a control (HepG2-scr). (A) The overexpression or inhibition of IDH2 in HepG2 cells was confirmed by RT-qPCR. (B-C) MMP9 levels in IDH2-modified HepG2 cells, by RT-qPCR (B), and by ELISA (C). (D) MMP9 activity in IDH2-modified HepG2 cells, by MMP9 activity assay. (E-F) Transwell cell invasion assay, shown by quantification (E), and by representative images (F). ${ }^{*} \mathrm{p}<0.05, \mathrm{~N}=5$.
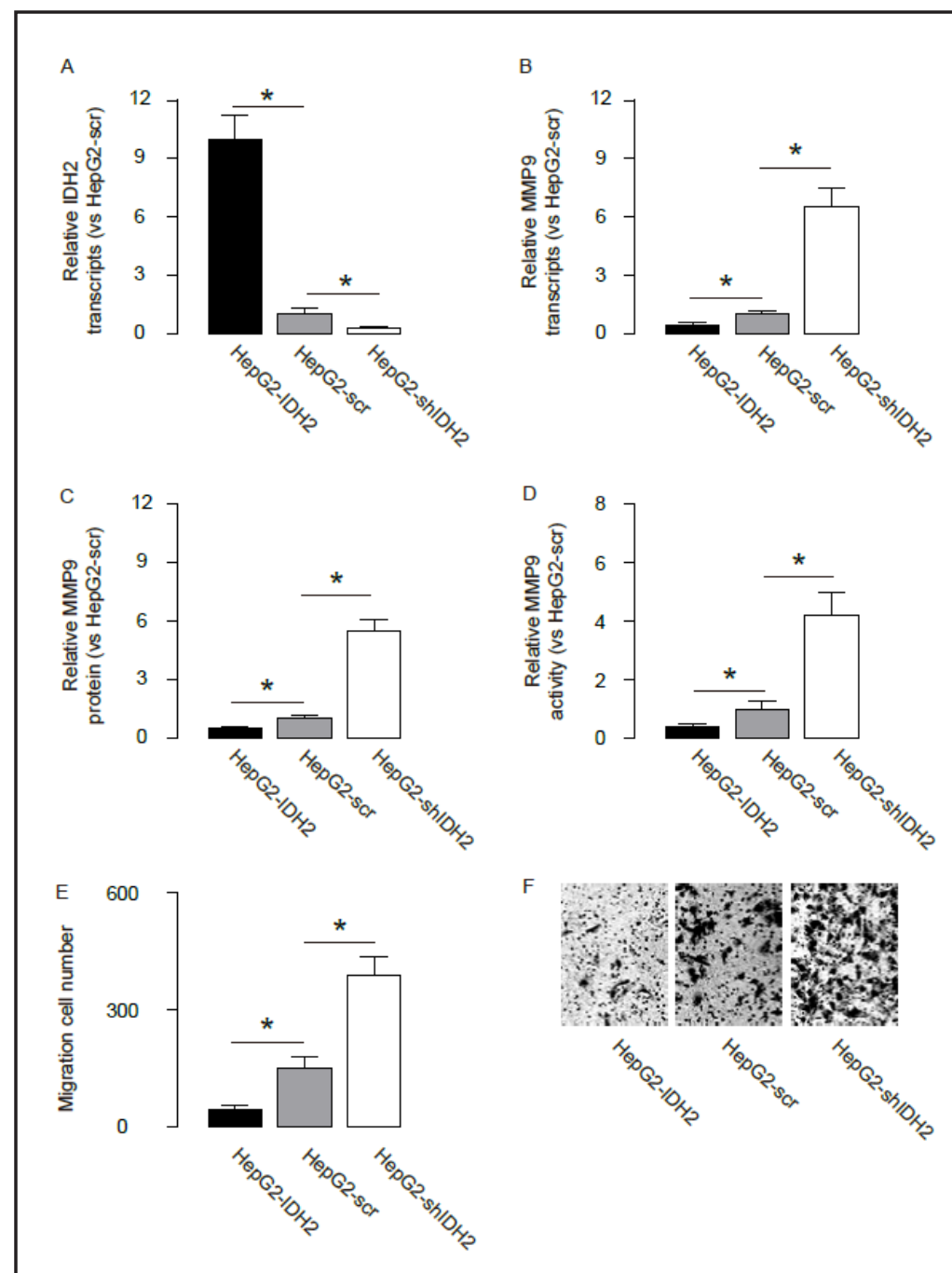

levels, by RT-qPCR (Fig. 2B), and by Western blot (Fig. 2C). These data suggest that MMP9 does not regulate IDH2 in HCC cells.

\section{IDH2 inhibits MMP9 in HCC cells}

Next, we either overexpressed IDH2 by expression of IDH2 transgene (HepG2-IDH2), or inhibited IDH2 by expression of IDH2 shRNA (HepG2-shIDH2), through lipofectaminemediated transfection of HepG2 cells. The HepG2 cells were also transfected with a plasmid carrying a scrambled sequence as a control (HepG2-scr). The overexpression or inhibition of IDH2 in HepG2 cells was confirmed by RT-qPCR (Fig. 3A). We found that overexpression of IDH2 significantly decreased MMP9 levels in HepG2 cells, while inhibition of IDH2 significantly increased MMP9 levels in HepG2 cells, by RT-qPCR (Fig. 3B), and by ELISA (Fig. 3C). Moreover, the IDH2-regulated changes in MMP9 resulted in changes in MMP9 activity (Fig. 3D). Thus, these data suggest that IDH2 inhibits MMP9 in HCC cells. Furthermore, the IDH2-regulated alterations in MMP9 levels resulted in changes in cell invasion in a transwell cell invasion assay, shown by quantification (Fig. 3E), and by representative images (Fig. 3F). Hence, IDH2 regulates HCC cell invasion through MMP9.

\section{IDH2 inhibits MMP9 in HCC cells through NF- $\kappa B$ pathway}

Then we examined the underlying mechanisms. First, modification of IDH2 levels in IDH2-modified HCC cells was confirmed (Fig. 4A-B). We found that increases in IDH2 in HCC cells decreased p65, a major NF- $\kappa B$ player. On the other hand, decreases in IDH2 in HCC 
Fig. 4. IDH2 inhibits MMP9 in HCC cells through NF- $\mathrm{KB}$ pathway. In order to see whether $N F-\kappa B$ signaling is required for the regulation of MMP9 by IDH2, we gave MG132, a NF- $\kappa$ B signaling inhibitor, to IDH2-depleted HepG2 cells. Western blot was performed and shown by representative blots (A), and by quantification for IDH2 (B), p65 (C), MMP9 (D), iNOS (E) and iкB (F). ${ }^{*} \mathrm{p}<0.05$. NS: non-significant, $\mathrm{N}=5$.

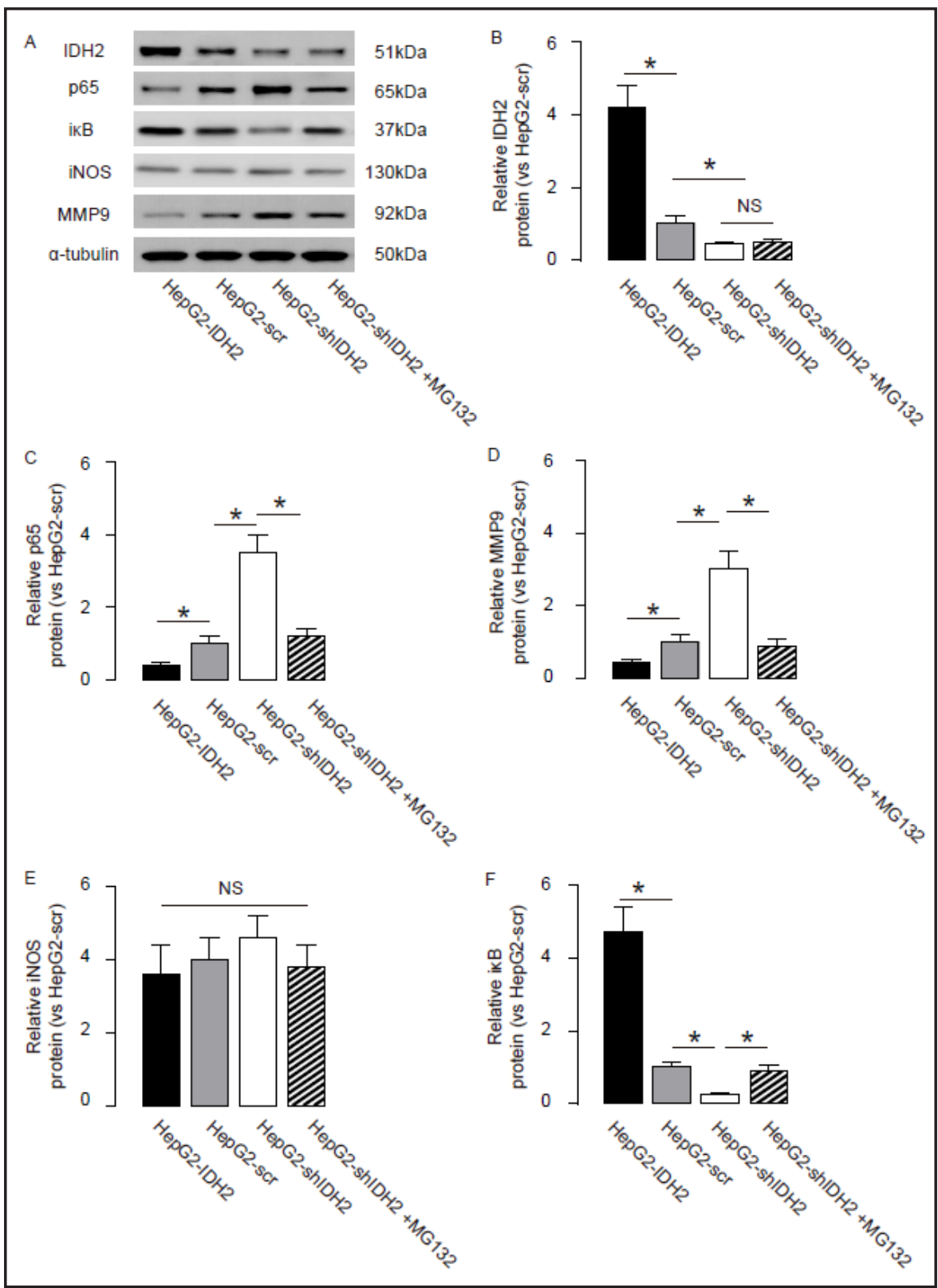

cells increased p65 (Fig. 4A, C). In order to see whether NF- $\kappa B$ signaling is required for the regulation of MMP9 by IDH2, we gave MG132, a NF- $\kappa$ B signaling inhibitor, to IDH2-depleted HepG2 cells. We found that inhibition of NF- $\kappa B$ signaling did not alter IDH2 levels, but abolished the activation of p65, and abolished the activation of MMP9 (Fig. 4A, B, D). Since IDH2 has been implicated in the control of oxidative stress and one of the main mechanisms of NF-kB activation is via ROS, we thus examined iNOS levels after the overexpression or depletion of IDH2, and found that iNOS levels were not changed by IDH2 modification (Fig. $1 \mathrm{~A}, \mathrm{E})$. Therefore, these data do not support that oxidative stress may collaborate with IDH2 to regulate MMP9 and NF-kB activation in HCC cells. Since the proteasome inhibitor MG132 blocks activation of NF- $\kappa$ B by preventing degradation of $I \kappa B$, we thus examined the expression of ikB in both IDH2-overexpressed or IDH2-depleted HepG2 cells. Our data showed that increases in IDH2 in HCC cells increased ikB, and decreases in IDH2 in HCC cells decreased ikB (Fig. 4A, C). Thus, IDH2 inhibits MMP9 in HCC cells in a NF- $\kappa B$ signaling dependent manner, possibly through iкB, to suppress HCC cell invasion (Fig. 5). 


\section{Cellular Physiology Cell Physiol Biochem 2015;37:2405-2414 \begin{tabular}{l|l|l} 
and Biochemistry 2015 The Author(s). Published by S. Karger AG, Basel \\
Published
\end{tabular}

Fig. 5. A Schematic model. IDH2 inhibits MMP9 in HCC cells in a NF- $\kappa B$ signaling dependent manner, possibly through ikB, to suppress HCC cell invasion.

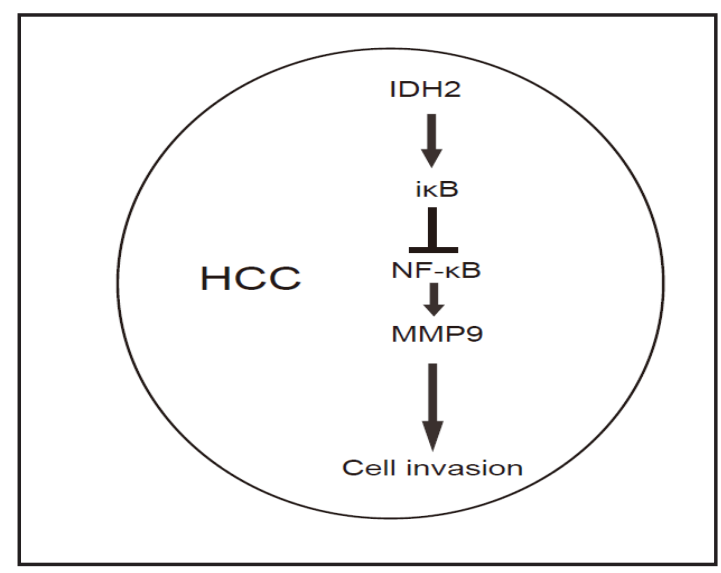

\section{Discussion}

HCC is one of the most prevalent human cancers. The alteration of IDH2 levels has been identified in several types of carcinoma. However, the expression and significance of IDH2 in HCC is still unknown. Moreover, the molecular mechanisms underlying the IDH2-regulated cancer cell metastases are so far poorly understood.

Here, we first confirmed that the level of IDH2 was significantly decreased in HCC tissues, compared with the adjacent normal tissues from human patients. Moreover, from examination of key MMPs, we detected significant upregulation of MMP9 in HCC. MMPs have been well-known to control cell metastasis. Since we want to know whether IDH2 plays a role in control of HCC metastasis, we examined the correlation between MMP9 and IDH2 in HCC. A strong negative correlation prompted us to test a causal link.

We thus modified IDH2 levels in a HCC cell line, and found that it directly affected the levels of MMP9. Moreover, by inhibiting NF-кB pathway, we completely inhibited the effect of IDH2 on MMP9. Nuclear factor- $\kappa \mathrm{B}(\mathrm{NF}-\kappa \mathrm{B})$ has been well recognized as a pivotal regulator of cancer initiation, progression and invasion, whereas recent developments have shown a broad involvement of NF- $\kappa B$ in other aspects of cancer pathology. NF- $\kappa B$ is a group of dimeric transcription factors comprised of the Rel family of proteins that include RelA (p65), c-Rel,

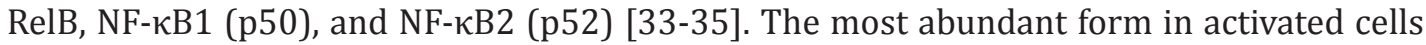
is the RelA/NF- $\kappa B 1$ (p65/p50) heterodimer, referred to as 'classic' NF- $\kappa B$ [33-35]. NF- $\kappa B$ resides in the cytoplasm in a latent form, and translocate to the nucleus to function upon stimulation [33-35]. The cytoplasmic retention of NF- $\kappa B$ results from its interaction with

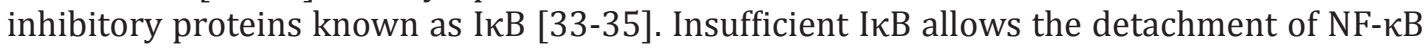
from $I \kappa B$, and its subsequent entering the nucleus to initiate gene transcription [33-35]. Indeed, by examination of the possible involved pathways, the effects of NF- $\kappa \mathrm{B}$ pathway in the regulation of MMP9 by IDH2 were most pronounced, compared to JNK, ERK/MARK, or PI3k signaling pathway. Thus, we conclude that IDH2 may inhibit MMP9 activation in HCC

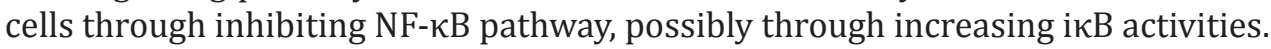

The limitation of this study rests on that it is a retrospective study including a relative small number of patients' specimen. In addition, the lower IDH2 levels in HCC specimens do not necessarily indicate a mutation in this gene. Furthermore, gain-of-function and lossof-function experiments using MMP9 or IDH2 were only performed in one cell line. Further studies are needed to confirm the precise molecular regulation of IDH2 and NF- $\kappa$ B and their interaction to elucidate the role of IDH2 in cell growth and its effects on cell invasion. In summary, our study highlights IDH2 as a novel therapeutic target for HCC treatment.

\section{Disclosure Statement}

The authors have declared that no competing interests exist. 


\section{Cellular Physiology Cell Physiol Biochem 2015;37:2405-2414

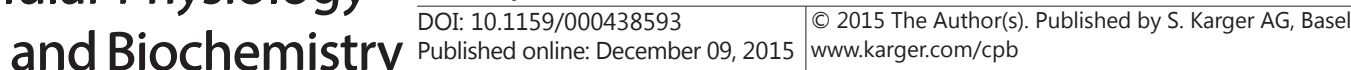 \\ Tian et al.: IDH2 Suppresses HCC Invasion via MMP9}

\section{References}

1 Yu C, Wang Z, Xu X, Xiang W, Huang X: Circulating hepatocellular carcinoma cells are characterized by cxcr4 and mmp26. Cell Physiol Biochem 2015;36:2393-2402.

2 Ge Z, Zhang B, Bu X, Wang Y, Xiang L, Tan J: Molecular mechanism of activating protein-4 regulated growth of hepatocellular carcinoma. Tumour Biol 2014;35:12441-12447.

3 Sun R, Luo Y, Li J, Wang Q Li J, Chen X, Guan K, Yu Z: Ammonium chloride inhibits autophagy of hepatocellular carcinoma cells through smad2 signaling. Tumour Biol 2015;36:1173-1177.

4 Wang J, Su H, Han X, Xu K: Inhibition of fibroblast growth factor receptor signaling impairs metastasis of hepatocellular carcinoma. Tumour Biol 2014;35:11005-11011.

5 Tang D, Sun B, Yu H, Yang Z, Zhu L: Tumor-suppressing effect of mir-4458 on human hepatocellular carcinoma. Cell Physiol Biochem 2015;35:1797-1807.

6 Shen Y, Wei Y, Wang Z, Jing Y, He H, Yuan J, Li R, Zhao Q Wei L, Yang T, Lu J: Tgf-beta regulates hepatocellular carcinoma progression by inducing treg cell polarization. Cell Physiol Biochem 2015;35:1623-1632.

7 Yao Y, Dou C, Lu Z, Zheng X, Liu Q: Macc1 suppresses cell apoptosis in hepatocellular carcinoma by targeting the hgf/c-met/akt pathway. Cell Physiol Biochem 2015;35:983-996.

8 Zheng Y, Chen H, Yin M, Ye X, Chen G, Zhou X, Yin L, Zhang C, Ding B: Mir-376a and histone deacetylation 9 form a regulatory circuitry in hepatocellular carcinoma. Cell Physiol Biochem 2015;35:729-739.

9 Cui SX, Zhang YS, Chu JH, Song ZY, Qu XJ: Des-gamma-carboxy prothrombin (dcp) antagonizes the effects of gefitinib on human hepatocellular carcinoma cells. Cell Physiol Biochem 2015;35:201-212.

10 Luo L, Xie Y, Wang A, Liu X, Xiao F, Zhong X, Zhong C: Desipramine ameliorates cr(vi)-induced hepatocellular apoptosis via the inhibition of ceramide channel formation and mitochondrial ptp opening. Cell Physiol Biochem 2014;34:2128-2136.

11 Zhang YS, Chu JH, Cui SX, Song ZY, Qu XJ: Des-gamma-carboxy prothrombin (dcp) as a potential autologous growth factor for the development of hepatocellular carcinoma. Cell Physiol Biochem 2014;34:903-915.

12 Jiang HL, Xu D, Yu H, Ma X, Lin GF, Ma DY, Jin JZ: Dax-1 inhibits hepatocellular carcinoma proliferation by inhibiting beta-catenin transcriptional activity. Cell Physiol Biochem 2014;34:734-742.

13 Zhou J, Lu S, Yang S, Chen H, Shi H, Miao M, Jiao B: Microrna-127 post-transcriptionally downregulates sept7 and suppresses cell growth in hepatocellular carcinoma cells. Cell Physiol Biochem 2014;33:15371546.

14 Lokody I: Metabolism: Idh2 drives cancer in vivo. Nat Rev Cancer 2013;13:756-757.

15 Chen C, Liu Y, Lu C, Cross JR, Morris JPt, Shroff AS, Ward PS, Bradner JE, Thompson C, Lowe SW: Cancerassociated idh2 mutants drive an acute myeloid leukemia that is susceptible to brd4 inhibition. Genes Dev 2013;27:1974-1985.

16 Lv Q, Xing S, Li Z, Li J, Gong P, Xu X, Chang L, Jin X, Gao F, Li W, Zhang G, Yang J, Zhang X: Altered expression levels of idh2 are involved in the development of colon cancer. Exp Ther Med 2012;4:801-806.

17 Borodovsky A, Seltzer MJ, Riggins GJ: Altered cancer cell metabolism in gliomas with mutant idh1 or idh2. Curr Opin Oncol 2012;24:83-89.

18 Marcucci G, Maharry K, Wu YZ, Radmacher MD, Mrozek K, Margeson D, Holland KB, Whitman SP, Becker H, Schwind S, Metzeler KH, Powell BL, Carter TH, Kolitz JE, Wetzler M, Carroll AJ, Baer MR, Caligiuri MA, Larson RA, Bloomfield CD: Idh1 and idh2 gene mutations identify novel molecular subsets within de novo cytogenetically normal acute myeloid leukemia: A cancer and leukemia group b study. J Clin Oncol 2010;28:2348-2355.

19 van den Bent MJ, Dubbink HJ, Marie Y, Brandes AA, Taphoorn MJ, Wesseling P, Frenay M, Tijssen CC, Lacombe D, Idbaih A, van Marion R, Kros JM, Dinjens WN, Gorlia T, Sanson M: Idh1 and idh2 mutations are prognostic but not predictive for outcome in anaplastic oligodendroglial tumors: A report of the european organization for research and treatment of cancer brain tumor group. Clin Cancer Res 2010;16:1597-1604.

20 Reitman ZJ, Yan H: Isocitrate dehydrogenase 1 and 2 mutations in cancer: Alterations at a crossroads of cellular metabolism. J Natl Cancer Inst 2010;102:932-941.

21 Gross S, Cairns RA, Minden MD, Driggers EM, Bittinger MA, Jang HG, Sasaki M, Jin S, Schenkein DP, Su SM, Dang L, Fantin VR, Mak TW: Cancer-associated metabolite 2-hydroxyglutarate accumulates in acute myelogenous leukemia with isocitrate dehydrogenase 1 and 2 mutations. J Exp Med 2010;207:339-344.

22 Mao Y, Cheng J, Yu F, Li H, Guo C, Fan X: Ghrelin attenuated lipotoxicity via autophagy induction and nuclear factor-kappab inhibition. Cell Physiol Biochem 2015;37:563-576. 


\section{Cellular Physiology Cell Physiol Biochem 2015;37:2405-2414 \begin{tabular}{ll|l} 
DOI: 10.1159/000438593 & $\begin{array}{l}\text { O 2015 The Author(s). Published by S. Karger AG, Basel } \\
\text { www.karger.com/cpb }\end{array}$
\end{tabular} \\ Tian et al.: IDH2 Suppresses HCC Invasion via MMP9}

23 Orabi AI, Sah S, Javed TA, Lemon KL, Good ML, Guo P, Xiao X, Prasadan K, Gittes GK, Jin S, Husain SZ: Dynamic imaging of pancreatic nuclear factor kappab (nf-kappab) activation in live mice using adenoassociated virus (aav) infusion and bioluminescence. J Biol Chem 2015;290:11309-11320.

24 Moe KT, Khairunnisa K, Yin NO, Chin-Dusting J, Wong P, Wong MC: Tumor necrosis factor-alpha-induced nuclear factor-kappab activation in human cardiomyocytes is mediated by nadph oxidase. J Physiol Biochem 2014;70:769-779.

25 Lee SJ, Cho SC, Lee EJ, Kim S, Lee SB, Lim JH, Choi YH, Kim WJ, Moon SK: Interleukin-20 promotes migration of bladder cancer cells through extracellular signal-regulated kinase (erk)-mediated mmp-9 protein expression leading to nuclear factor (nf-kappab) activation by inducing the up-regulation of p21(waf1) protein expression. J Biol Chem 2013;288:5539-5552.

26 Kong D, Li Y, Wang Z, Banerjee S, Sarkar FH: Inhibition of angiogenesis and invasion by 3,3'-diindolylmethane is mediated by the nuclear factor-kappab downstream target genes mmp-9 and upa that regulated bioavailability of vascular endothelial growth factor in prostate cancer. Cancer Res 2007;67:3310-3319.

27 Li Y, Kucuk O, Hussain M, Abrams J, Cher ML, Sarkar FH: Antitumor and antimetastatic activities of docetaxel are enhanced by genistein through regulation of osteoprotegerin/receptor activator of nuclear factor-kappab (rank)/rank ligand/mmp-9 signaling in prostate cancer. Cancer Res 2006;66:4816-4825.

28 Chen Y, Jiang T, Mao A, Xu J: Esophageal cancer stem cells express plgf to increase cancer invasion through mmp9 activation. Tumour Biol 2014;35:12749-12755.

29 Jian H, Zhao Y, Liu B, Lu S: Sema4b inhibits mmp9 to prevent metastasis of non-small cell lung cancer. Tumour Biol 2014;35:11051-11056.

30 Pei J, Lou Y, Zhong R, Han B: Mmp9 activation triggered by epidermal growth factor induced foxo1 nuclear exclusion in non-small cell lung cancer. Tumour Biol 2014;35:6673-6678.

31 Song H, Tian Z, Qin Y, Yao G, Fu S, Geng J: Astrocyte elevated gene-1 activates mmp9 to increase invasiveness of colorectal cancer. Tumour Biol 2014;35:6679-6685.

32 Wang F, Xiao W, Sun J, Han D, Zhu Y: Mirna-181c inhibits egfr-signaling-dependent mmp9 activation via suppressing akt phosphorylation in glioblastoma. Tumour Biol 2014;35:8653-8658.

33 Feldmann M, Andreakos E, Smith C, Bondeson J, Yoshimura S, Kiriakidis S, Monaco C, Gasparini C, Sacre S, Lundberg A, Paleolog E, Horwood NJ, Brennan FM, Foxwell BM: Is nf-kappab a useful therapeutic target in rheumatoid arthritis? Ann Rheum Dis 2002;61:ii13-18.

34 van Loo G, Beyaert R: Negative regulation of nf-kappab and its involvement in rheumatoid arthritis. Arthritis Res Ther 2011;13:221.

35 Roman-Blas JA, Jimenez SA: Nf-kappab as a potential therapeutic target in osteoarthritis and rheumatoid arthritis. Osteoarthritis Cartilage 2006;14:839-848. 